\title{
Rotosonde: Acquiring Vertical Wind Profile of a Tropical Cyclone with Small Unmanned Helicopters
}

\author{
Chung-Kiak Poh, Chung-How Poh \\ Aero-Persistence Research, Penang, Malaysia \\ Email:kiak@aero-persistence.com
}

How to cite this paper: Poh, C.-K. and Poh, C.-H. (2017) Rotosonde: Acquiring Vertical Wind Profile of a Tropical Cyclone with Small Unmanned Helicopters. Advances in Aerospace Science and Technology, 2, 17-22.

https://doi.org/10.4236/aast.2017.22002

Received: March 12, 2017

Accepted: April 30, 2017

Published: May 2, 2017

Copyright $\odot 2017$ by authors and Scientific Research Publishing Inc. This work is licensed under the Creative Commons Attribution International License (CC BY 4.0).

http://creativecommons.org/licenses/by/4.0/

\begin{abstract}
Spinsonde is a chute-free vertical retardation technique specifically developed for fixed-wing unmanned aircraft to acquire accurate measurement of vertical wind speed profile for meteorological applications. Key advantages of spinsonde over the expendable chute-operated dropsondes are the ability to acquire multi-cycle measurement, efficient use of payload capacity and cost-effectiveness. This work proposes the concept of "rotosonde", which is the spinsonde equivalent for unmanned helicopters. Computer simulations are carried out to evaluate the performance of the rotosonde and results indicate that the measured speed generally correlates with the wind speed to within \pm 3 $\mathrm{km} \cdot \mathrm{h}^{-1}$ even for intensities in excess of $180 \mathrm{~km} \cdot \mathrm{h}^{-1}$. The profound implication of this work is that unmanned helicopters can now be considered for important field of studies such as cyclogenesis given their reliability to operate in gusty wind conditions in remote oceans, particularly during docking and launching from carriers.
\end{abstract}

\section{Keywords}

Rotosonde, Spinsonde, Cyclogenesis, VTOL, Unmanned Helicopter

\section{Introduction}

Winds and clouds are part of the glory of the troposphere that mother Earth has endowed upon us. Remote sensing and in situ measurements help us to understand our atmosphere. Vertical wind speed profile is an essential in situ measurement especially in the study and prediction of severe weather such as tropical cyclones [1] [2]. Dropsondes have been commonly used to acquire vertical wind speed profile measurements [3] [4] [5]. The expendable dropsondes are designed to be dropped from an aircraft at altitude to measure atmospheric con- 
ditions as they fall to the surface. They typically contain a GPS receiver, along with other sensors to record atmospheric profiles [5]. From 40,000 ft (12,192 m) down to sea-level, the descent rate of the dropsonde varied from about 28 to 11.5 $\mathrm{ms}^{-1}$ [2]. Spinsonde technique based on the stall-spin maneuver of fixed-wing aerobatic aircraft has recently been proposed and demonstrated to have the ability to measure vertical wind speed profile similar to a dropsonde [6] [7] [8]. The hallmark of the chute-free spinsonde approach is that it enables acquisition of multi-cycle measurement using only a single airplane and hence being cost-effective [6]. Furthermore, the bulky storage space for the dropsondes is eliminated which translates to optimum use of payload capacity e.g. to carry additional onboard fuel or batteries to enhance flight endurance [6]. Spinsonde-capable unmanned airplane with a wing loading of $227 \mathrm{~g} \cdot \mathrm{dm}^{-2}$ has a simulated descent rate of $9.8 \mathrm{~ms}^{-1}$ and a $\mathrm{V}_{\mathrm{H}}$ of $355 \mathrm{~km} \cdot \mathrm{h}^{-1}$ (without drop tanks) [7]. It is also interesting to note that unmanned airplane equipped with PTVC-M was able to climb while gyrating in the stall-spin [8]. Small unmanned helicopters (main rotor spans: 550 to $800 \mathrm{~mm}$ ) are highly agile and have a reasonably good tolerance to gusty winds during flight and while docking on mobile carriers. Thus, they can be considered for autonomous missions that require high reliability and low maintenance such as weather reconnaissance in remote regions of the oceans. Additionally, a single-rotor model helicopter has attained a world speed record of $311 \mathrm{~km} \cdot \mathrm{h}^{-1}$ [9] which, in our opinion, is adequate for typhoon missions.

As part of the Cost-effective Typhoon Reconnaissance Program Initiative by Aero-Persistence Research PLT we hereby propose the use of small unmanned helicopter as viable candidate to perform spinsonde function and we term the maneuver as "rotosonde". The maneuver will be evaluated and demonstrated via computer simulation using a single-rotor radio controlled (RC) helicopter under various wind conditions.

\section{Materials and Methods}

\section{Simulation Details}

The computer simulation work was performed using the RealFlight ${ }^{\otimes 1} 6.5$ simulator [10]. It employs RealPhysics ${ }^{\text {Tw }}$ technology for accurate and realistic simulations [10]. The as-supplied simulation model Dominion 90 3D FBL was used as the RC model helicopter to demonstrate the concept of rotosonde, as shown in Figure 1. It used the $\mathrm{SAB} 710 \mathrm{~mm}$ rotor blade with a rotor diameter of $1.78 \mathrm{~m}$ and a disk loading of $22.76 \mathrm{~g} \cdot \mathrm{dm}^{-2}$.

As with most modern RC helicopters, the Dominion 90 3D used the electronic flybar flight stabilization system, often loosely abbreviated within the RC community as FBL (flybarless). The flight stabilization unit also has a built-in gyro for the yaw control. The gyro gains for the cyclic controls (aileron and elevator) were unaltered, but the gain for the yaw control was turned off completely during rotosonde evaluation. The helicopter was flown in manually piloted mode. ${ }^{1}$ RealFlight is a registered trademark of Hobbico, Inc. used with permission. 


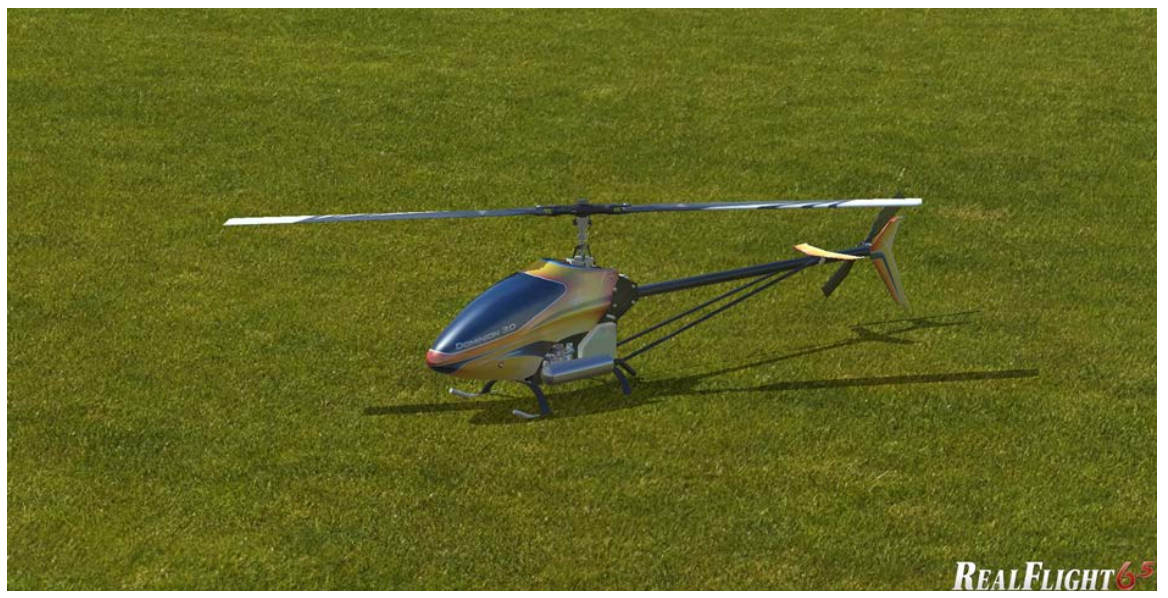

Figure 1. Computer model of the as-supplied Dominion 90 3D FBL.

To investigate the ability of the rotosonde to reliably detect wind speed, the simulations were performed with horizontal wind intensity values set to 0 and greater than $180 \mathrm{~km} \cdot \mathrm{h}^{-1}$. On-screen simulation results were recorded and compiled into video clips using the Camtasia ${ }^{\oplus} 9$ software.

\section{Simulation Results and Discussion}

\section{Characterization of the Rotosonde Performance}

This section investigates the effectiveness of rotosonde technique in measuring the vertical wind speed profile. Following [6], the measured atmospheric wind speed would be equated with the ground speed of the helicopter, which in turn would be equivalent to the speed measurement acquired by the onboard GPS receiver unit if it were in real field testing. The rotosonde maneuver was initiated while the helicopter was in cruising flight. The maneuver began with autorotation in which negative collective pitch was applied, to be followed by slight displacements of rudder and aileron in the same direction (in this case, right) which would gradually reduce the forward airspeed of the helicopter to practically zero.

The simulated test was first carried out with horizontal wind speed of $0 \mathrm{~km} \cdot \mathrm{h}^{-1}$ as shown in Video 1 . The cruising speed of the helicopter was about $68 \mathrm{~km} \cdot \mathrm{h}^{-1}$ as indicated by the ground speed in the "NavGuides" located on top left corner of the video. Once the spin began, the ground speed rapidly decayed to less than 5 $\mathrm{km} \cdot \mathrm{h}^{-1}$ within a time frame of $10 \mathrm{~s}$. Once equilibrium has been reached, the variation between the ground speed and the wind speed was $\pm 2 \mathrm{~km} \cdot \mathrm{h}^{-1}$ which was taken as the measurement uncertainty of the wind speed. As the yaw gyro was deactivated, the helicopter was allowed to pirouette freely and we believed this approach has played a significant role in providing the required dynamic stability to the rotosonde maneuver. As a consequence, the helicopter achieved a very consistent yaw rate and nose angle and thereby keeping the measurement uncertainty to a minimum (Video 1).

The variometer showed that the rotosonde achieved a descent rate of about 10 
$\mathrm{ms}^{-1}$, which was slower than that of the dropsonde at near sea-level $\left(11.5 \mathrm{~ms}^{-1}\right)$ and this implied the possibility to acquire data with higher resolution. Figure 2(a) shows a screenshot of the Dominion 90 performing the rotosonde function at a descent rate of $9.5 \mathrm{~ms}^{-1}$. The helicopter pirouetted with a yaw rate of $287 \mathrm{~s}^{-1}$ and the rpm of the main rotor was 1315. The binocular gadget window on the left hand side of the image provides a magnified view of the helicopter in real-time.

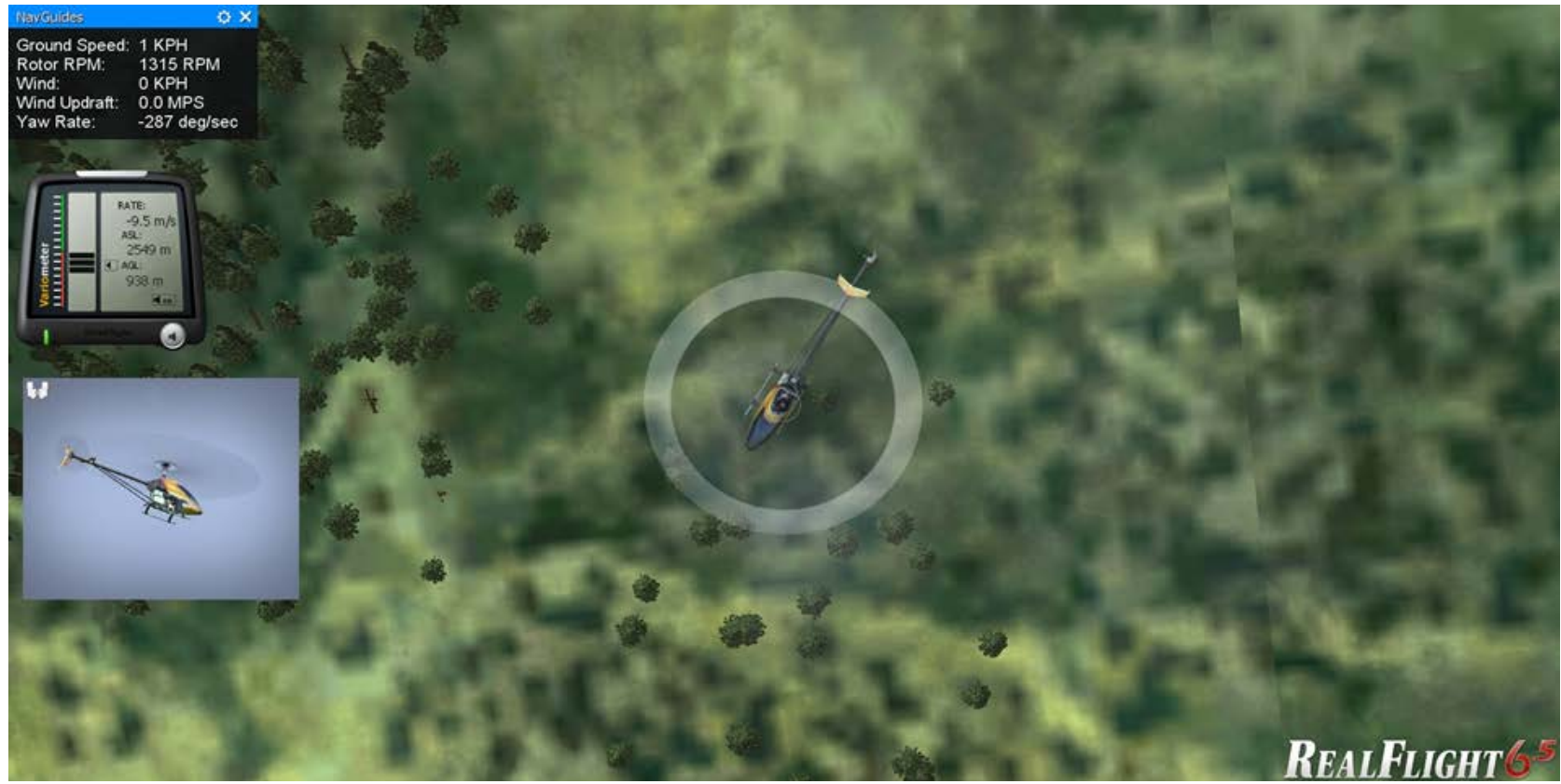

(a)

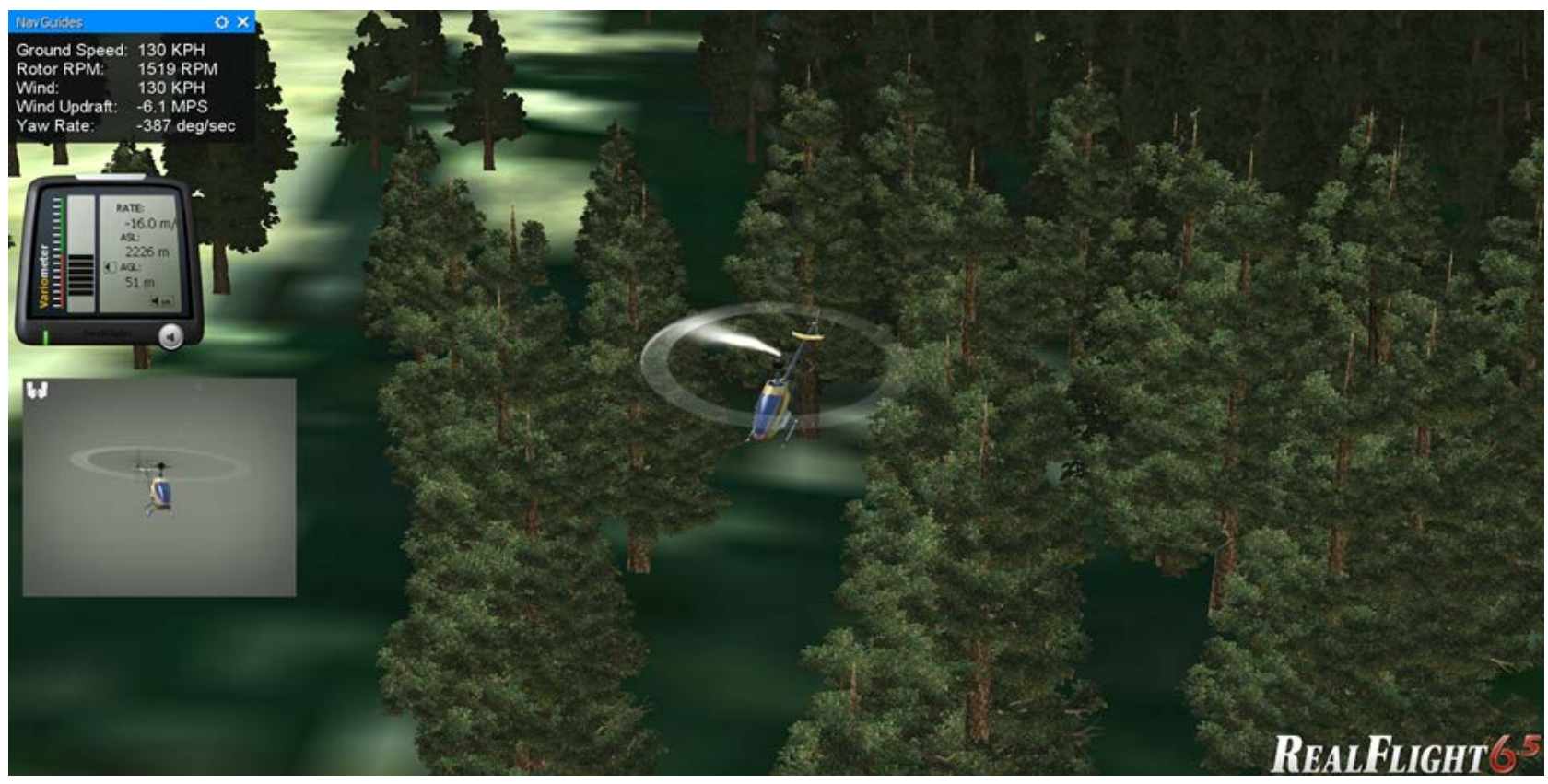

(b)

Figure 2. The Dominion 90 3D FBL performing the rotosonde function with horizontal wind speeds of (a) $0 \mathrm{~km} \cdot \mathrm{h}^{-1}$ and (b) 130 $\mathrm{km} \cdot \mathrm{h}^{-1}$. 
To evaluate the performance of the rotosonde in strong wind, the simulated wind speed was increased to its maximum value of $205 \mathrm{~km} \cdot \mathrm{h}^{-1}$ at $2729 \mathrm{~m}$ above sea level (altitude and terrain dependent) and the results are presented in Video 2. The local wind intensity increased with the altitude of the helicopter, and updrafts and downdrafts were also present primarily due to the influence of terrain. The strength of the updraft is indicated in the NavGuide in the unit of $\mathrm{ms}^{-1}$. The local wind intensity when the rotosonde maneuver began was about $193 \mathrm{~km} \cdot \mathrm{h}^{-1}$. The rotosonde performed exceptionally well with the uncertainty settled to \pm 5 $\mathrm{km} \cdot \mathrm{h}^{-1}$ (predominantly $\pm 3 \mathrm{~km} \cdot \mathrm{h}^{-1}$ ). This result also suggested that the uncertainty did not appear to be adversely affected by the variation in wind intensity, which was similar to the characteristic of the spinsonde. Reference [6] reported that the measurement uncertainty of the spinsonde remained within $\pm 5 \mathrm{~km} \cdot \mathrm{h}^{-1}$ even at a wind speed of $180 \mathrm{~km} \cdot \mathrm{h}^{-1}$. The pirouetting helicopter continued to drift with the wind as it made its descent onto a forested area with downdraft as high as $7.5 \mathrm{~ms}^{-1}$, yet the rotosonde retained its descent rate of approximately $10 \mathrm{~ms}^{-1}$ and an uncertainty of $\pm 3 \mathrm{~km} \cdot \mathrm{h}^{-1}$. The rotosonde maneuver was terminated at altitude below $100 \mathrm{~m}$ above ground level (AGL) to avoid the trees and power to the main rotor was resumed.

The Dominion 90 then began its gentle climb and making itself ready for another cycle of rotosonde. Screenshot of the helicopter as it descended towards the wooded area with local wind of $130 \mathrm{~km} \cdot \mathrm{h}^{-1}$ in a separate cycle is as shown in Figure 2(b).

Thus far, the rotosonde investigated herein has been operating in autorotation mode with a descent rate of about $10 \mathrm{~ms}^{-1}$. It would be of great interest to explore the concept of rotosonde in powered mode with the possibility of achieving a much slower descent rate or even a positive climb rate, similar to those accomplished by PTVC-M enabled spinsonde [8]. However, such detailed work is beyond the scope of this article and will be reported elsewhere.

\section{Conclusions}

Inspired by the spinsonde for fixed-wing aircraft, we had proposed and demonstrated via simulations the concept of rotosonde which would enable a small unmanned helicopter to be flown into a typhoon to acquire multiple traces of vertical wind speed profiles without having to rely on a chute as the dropsonde does. The rotosonde performed exceedingly well even at wind speed of 188 $\mathrm{km} \cdot \mathrm{h}^{-1}$ with high degree of accuracy (measurement uncertainty $\leq \pm 5 \mathrm{~km} \cdot \mathrm{h}^{-1}$ ). It is our belief that allowing the helicopter to pirouette freely during the rotosonde maneuver has played a significant role in providing the required dynamic stability and attaining low measurement error. This work has opened up the exciting possibility of unmanned helicopters joining the airplanes to acquire in situ measurements of our atmosphere.

\section{References}

[1] Franklin, J.L., Black, M.L. and Valde, K. (2003) GPS Drop Windsonde Wind Pro- 
files in Hurricanes and Their Operational Implications. Weather and Forecasting, $18,32-44$

https://doi.org/10.1175/1520-0434(2003)018<0032:GDWPIH>2.0.CO;2

[2] The National Center for Atmospheric Research (2017) What Is a Dropsonde? https://www.eol.ucar.edu/content/what-dropsonde

[3] NASA (2014) HS3 Hurricane Mission. http://www.nasa.gov/mission_pages/hurricanes/missions/hs3/

[4] Hock, T. (2012) NCAR/NSF GV New Automated Dropsonde System Overview. http://www.eol.ucar.edu/projects/mpex/meetings/2012Dec/presentations/04_Hock. pdf

[5] Wikipedia (2017) Dropsonde. http://en.wikipedia.org/wiki/Dropsonde

[6] Poh, C.-K. and Poh, C.-H. (2015) Concept of Spinsonde for Multi-Cycle Measurement of Vertical Wind Profile of Tropical Cyclones. Open Journal of Applied Sciences, 5, 145-150. https://doi.org/10.4236/ojapps.2015.54015

[7] Poh, C.-K. and Poh, C.-H. (2016) Journey to the Typhoon. Advances in Aerospace Science and Technology, 1, 21-31. https://doi.org/10.4236/aast.2016.11003

[8] Poh, C.-K. and Poh, C.-H. (2016) PTVC-M for Ultra-Agile VTOL and 300+ $\mathrm{km} \cdot \mathrm{h}^{-1}$ Cruising. Advances in Aerospace Science and Technology, 1, 48-57. https://doi.org/10.4236/aast.2016.11005

[9] RC Media World (2016) World Record RC Heli Speed-flight. https://www.youtube.com/watch?v=kMISGDRzN1Y

[10] Great Planes ${ }^{\circledast}$ Model Mfg. (2017) RealFlight ${ }^{\circledR}$ Radio Control Flight Simulator. http://www.realflight.com/

Submit or recommend next manuscript to SCIRP and we will provide best service for you:

Accepting pre-submission inquiries through Email, Facebook, LinkedIn, Twitter, etc. A wide selection of journals (inclusive of 9 subjects, more than 200 journals)

Providing 24-hour high-quality service

User-friendly online submission system

Fair and swift peer-review system

Efficient typesetting and proofreading procedure

Display of the result of downloads and visits, as well as the number of cited articles

Maximum dissemination of your research work

Submit your manuscript at: http://papersubmission.scirp.org/

Or contact aast@scirp.org 